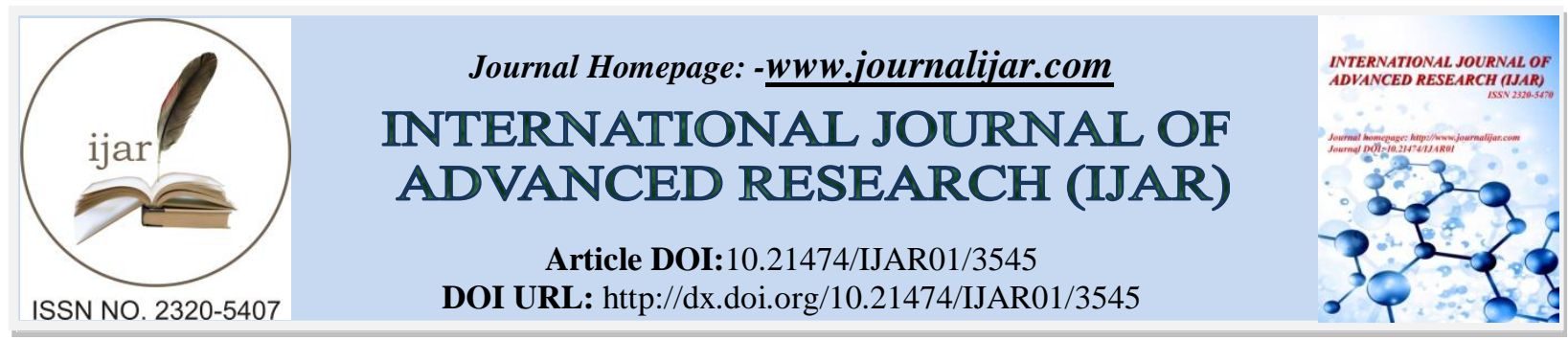

RESEARCH ARTICLE

\title{
THE EFFECT OF FRAGMENTATION IN VEGETATIVE AND ECOLOGICAL DYNAMISM OF MYRISTICA SWAMP - A FRAGILE FRESHWATER ECOSYSTEM OF WESTERN GHATS.
}

\author{
T.S. Vilas, C.S. Gokul and "M. Rajendraprasad.
}

Plant Systematics and Evolutionary Science Division, Jawaharlal Nehru Tropical Botanic Garden and Research Institute, Karimancode P.O., Palode, Thiruvananthapuram- 695 562, Kerala, India.

\section{Manuscript Info}

........................

Manuscript History

Received: 01 January 2017

Final Accepted: 03 February 2017

Published: March 2017

Key words:-

Ecosystem, Edaphic, Fragmentation, Myristica fatua var. magnifica, Myristica swamps, Western Ghats.

\section{Abstract}

A vast area of Western Ghats, coming under different forest types, are degraded and are threatened with ecological deprivation and biodiversity loss. Deforestation for urbanization, fragmentation due to developmental activities, over exploitation to meet the increased demand are the main anthropogenic threats. The freshwater swamps of Western Ghats dominated by the Myristicaceae members too face this loss of character. These ecosystems have unique biodiversity, bio wealth ecological functioning and supporting edaphic factors. Historically the natural landscape of Kerala is well represented by freshwater swamps and marshy lands which create a positive water regime and provide protection for unique flora and fauna. The high population density and high demand on space and livelihood of the state lead to the depletion or alteration of this natural landscape. In advanced stages, this leads to the fragmentation and isolation of the unique ecosystem. These changes in the ecological and edaphological characteristics will deprive these unique flora and fauna of the marshy condition to which it is adapted. The existing fragments of the freshwater swamp create a series of remnant patches, relic vegetation, surrounded by a matrix of different vegetation and by altered land use. Since Myristica swamps have been edaphically created with free flowing water stream, fragmentation initially results in the modification of velocity of water flow and changes in the silting or free flow of running water. The present investigation discusses the current distribution of swamps and its conservation status, ecological function and vegetational succession, by highlighting the effects of fragmentation and isolation of vegetation.

Copy Right, IJAR, 2017,. All rights reserved.

\section{Introduction:-}

Myristica swamps are edaphic formations of fresh water evergreen forest type coming under type category 4C/FSI (Champion and Seth, 1968) represented by a unique phytogeographic condition with supporting characteristics like amphibian vegetation. The predominant arboresent members are from primitive families like Myristicaceae, Flacourtiaceae,,Dipterocarpaceae, while the shrubby and herby flora is represented by members of advanced families like Araceae, Aricaceae, Zingiberaceae, Marantaceae, etc. The community status of Myristicaceae members

Corresponding Author:-M. Rajendraprasad. 
is structurally and functionally dominant over other members, hence, the name Myristica swamps. This water logged edaphic environment and associated vegetations are distributed in the valleys or foot hills of Western Ghats and subjected to seasonal flooding and silting. The evergreen members are amphibian in nature specially adapted for surviving in marshy water logged condition as well as in terrestrial condition. These swamps were reported from different states along the Western Ghats (Saldanha, 1984; Gadgil\&Chandran, 1989; Chandran\&Gadgil 1989; Chandran\&Mest, 2001; Vasudeva et al., 2001) Karnataka, Goa (Santhakumaran et al., 1995, 1999) and Kerala (Krishnamoorthy, 1960; Pascal, 1984). The ever green vegetation of swamps includes many endemic tree species and are well documented (Bourdillion, 1908; Sasidharan\&Sivarajan, 1996; Ramesh and Pascal, 1997; Chandran\& Mesta, 2011). The swamps are also inhabited by some of the red listed plants included in red data book of Indian plant (Nayar\&Sastry, 1987, 1990). Hence, the Myristica swamps, with pristine vegetation are virtually live museums of ancient life of great biological interest. During the historical events of development and urbanization, these forest lands have been exploited and obviously perished. Land use changes like conversion to paddy field or plantation of areca, coffee, rubber or submergence under irrigation projects or extermination due to fire, all have had adverse impacts on these swamps (Krishnamoorthy, 1960). The existing swamps are also heading towards extinction. An example of such anthropogenic activity is evident in the Sasthanada swamp, Sankili section, Kulathupuzha Forest Range, Trivandrum Forest Division having 12 patches, extending to an area of $0.223 \mathrm{sq} \mathrm{km}(22.29 \mathrm{Ha})$. The fragmentation involves dividing up of continuous ecosystem into smaller areas called patches, and each patch has a relatively homogenous floristic, ecologic, and edaphic conditions. When fragments are created, plant dynamics is modified owing to changes in the forest spatial organization, such as the size, shape, and type of isolation barrier of forest patches. The functional dynamism of patches are affected with edge effects, migration and establishment of new species, decrese in the recruitment rate of specific species and increased recruitment rate of flexible species and disturbances in faunal interactions and disproportionally favoured and hence dominating species like Lagerstromeaspeciosa and while others like Myristica fatua var. magnifica are facing local extinction. This vegetational, structural and functional changes are generating changes in the availability of water, nutrients, light, wind and other basic environmental factors by creating different degrees of ecological succession in the same area viz. Core vegetation, the unchanged original vegetation; Edge vegetation, representing transformed one. In between the core and the edge there is transitional vegetation, which are in different stage of succession. In short, the fragmentation due to this change in land use causes, the vegetation which once was supported by wetland (core vegetation) changing to the terrestrial area vegetation (edge vegetation). Thus the isolation and fragmentation of Myristica swamps lead to the breakup of these natural ecosystems into smaller patches of vegetation posing threat to their conservation status. Changes in the physical edaphology and micro climate will alter the reproductive phenology of the members of the original vegetation, especially biota like Myristica fatua var. magnifica. It is also noticed that this unique ecosystems are also seen as Sacred Grove, the patches of vegetation protected in the religious ground to avoid the perceived wrath of its resident God. The community status of flagship species viz. Myristica fatua var. magnifica fluctuates in advance with vegetational succession indicating past massive fragmentation of swamp during the urbanization of the state and thus these habitats can be described as "swampy relics" especially due to fragmentation and isolation followed by the vegetational succession, ecological and edaphological changes. The present study puts emphasis on the trends of vegetational succession due to fragmentation and effect of invasion of other species in the swamp.

\section{Methodology:-}

\subsection{Study area:-}

Kerala, the most south-westerly state of India, is located between latitudes $8^{\circ} 17^{\prime} 30^{\prime \prime}$ N. and $12^{\circ} 47^{\prime} 40^{\prime \prime}$ N. and longitudes $74^{\circ} 27^{\prime} 47^{\prime \prime} \mathrm{E}$. and $77^{\circ} 37^{\prime} 12^{\prime \prime} \mathrm{E}$. The state is isolated from the Deccan Plateau by the Western-Ghats, one of the biodiversity hotspots of India. The Myristica swamp of Sasthanada region, Sankili section of Kulathupuzha Forest Range $\left(8^{0} 45^{\prime} 82^{\prime}\right.$ N. and $77^{0} 10^{\prime} 55^{\prime}$ E.) is situated at an elevation of $155 \mathrm{MSL}$. The vegetation of this Myristica swamps is in the three stages of succession such as core (Figure legend A), transition (Figure legend B) and edge zone (Figure legend $\mathrm{C}$ ). 


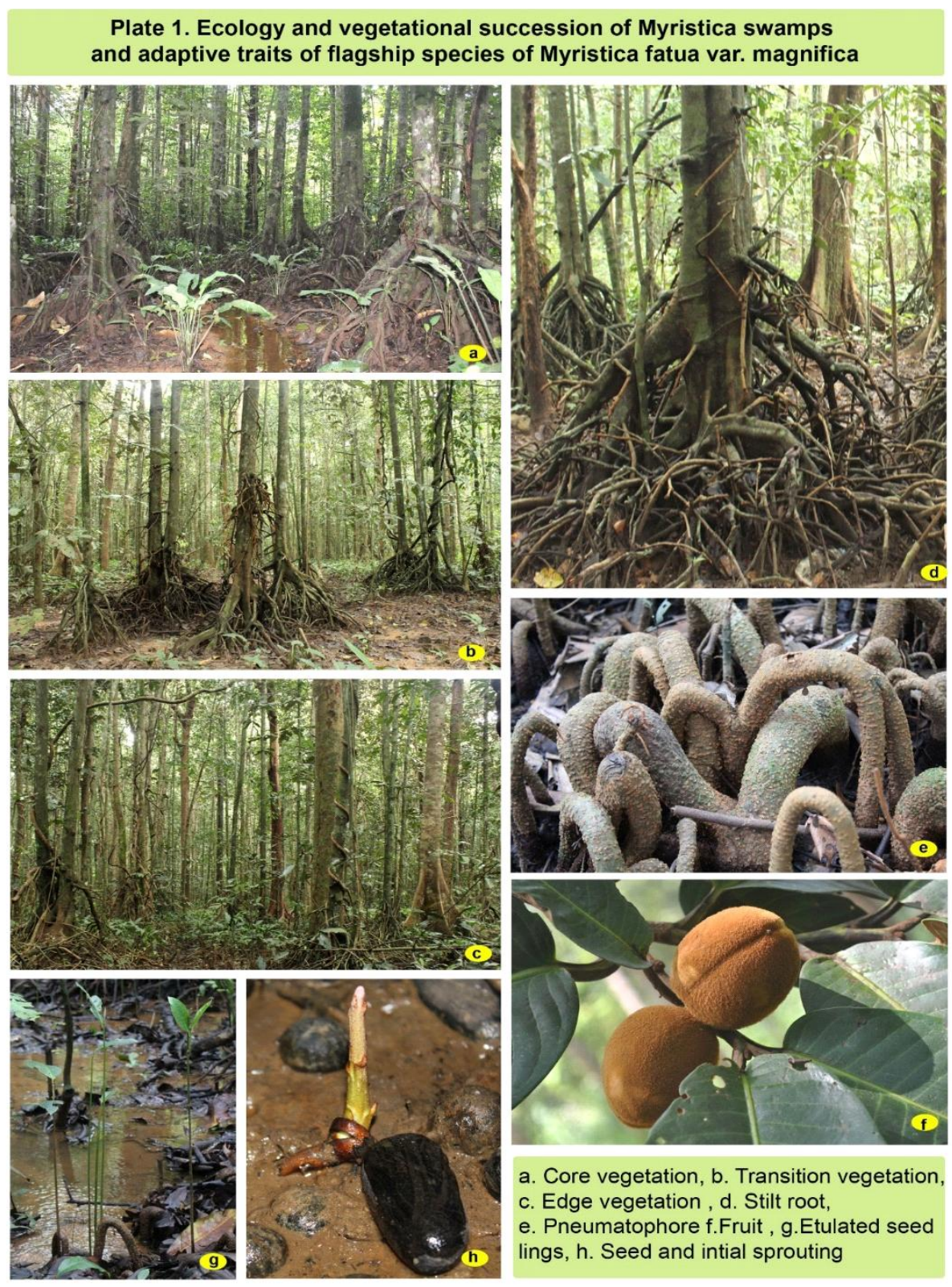

\subsection{Vegetation sampling:-}

A detailed exploration was made in entire study area. The vegetational type, floristic composition and anthropogenic pressure were identified. The whole area is divided into three regions the core, transition and edge area. The line transects were laid across all types. The phytosociological features and floristic status were assessed by laying quadrate of size $15 \times 10$ in random. All the members were identified and enumerated. Height and girth at breast height $(\mathrm{GBH})$ of all trees and shrubs $(\geq 10 \mathrm{~cm} \mathrm{GBH})$ were measured using clinometer and metallic measuring tape respectively. Vegetation with less than $10 \mathrm{~cm}$ GBH were counted and enumerated as seedlings or herb species. The identification of the species was done by referring authentic books. The following parameters were calculated using this vegetation data.

\subsection{Phytosociological analysis:-}

Relative frequency $(\mathrm{rF})$, Relative density ( $\mathrm{rd})$, Relative dominance $(\mathrm{rD})$ were calculated and summed up to get the Important Value Index (Barbour et al., 1947), the calculation is done by using the following formulae. 
Relative frequency $(r F)=$ Frequency of $i^{\text {th }}$ species $\quad x 100$

Total frequency of all the species

Relative density $(r d)=\quad$ No. of individuals of $i^{\text {th }}$ species $x 100$

Total frequency of all the species

Relative dominance $(r D)=$ Sum of the basal area of the individual of the $i^{\text {th }}$ species $x 100$

Total basal area of all the individuals

Basal area $=\frac{(G B H)^{2}}{4 \pi}$

Important Value Index $(I V I)=r F+r D+r d$

\subsection{Density:-}

The density of trees were found out by using point centred quadrate method (Barbour et al., 1971) Random points were located, the area around each point was divided into four $90^{\circ}$ quadrates and the nearest of each quadrate was marked. Average distance for all the trees were taken together and computed for density as per the formula given,

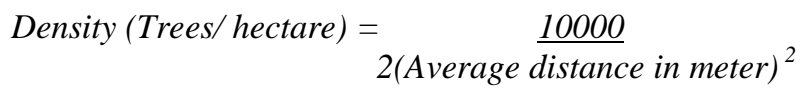

\subsection{Whiteford index:-}

It is the ratio of abundance and frequency. In general, an index value of 0.025 to 0.05 indicates that the species is random, while the value higher than 0.05 indicates increase in aggregation and value lower than 0.025 indicates a tendency towards regularity (Whiteford, 1948). It was calculated using the formula.

Whiteford index $=$ Abundance

Frequency

Frequency $=$ Total no. of quadrates in which species occurred $x$

$$
\text { Total no. of quadrates studie }
$$

Abundance $=\quad$ Total no. individuals of species

Total no. of quadrates occurrence

2.6. Similarity index:-

The value of similarity index indicates the affinity between each community. It is derived by the formula of Sorenson (1948).

Similarity index $=2 x$ No. of common species

Total no. species

\subsection{Floristic diversity indices:-}

The species diversity within a species, community or within a habitat is calculated to assess the biodiversity. The diversity comprises of two components via, species richness and evenness or equitability. A number of indices have been reported which measure both components of species diversity, i.e. Species richness and evenness into a single index. They are discussed below.

\subsubsection{Simpson's index $(D)$ :-}

The index measures the probability that two individuals selected at random from a sample will belong to the same species and range from 0-1 (Simpson, 1949).

$D=1-\sum_{I=1}^{S}[n i / N]^{2}$

$n i=$ Number of individuals

$N=$ total number of species

\subsubsection{Shannon- Wiener Index (H'):-}


This index of diversity is based on information theory. The information content is measure of the amount of uncertainty. The index is zero and maximum when all the species are represented by the same number of individuals. It generally falls between 1.5 to 3.5 and rarely exceeds 4.5 (Shannon- Wiener, 1963).

$H^{\prime}=-\sum_{I=1 N}^{S}\left\lceil\left(\frac{n i}{N}\right) \operatorname{In}(n i / N)\right.$

$n i=$ Number of individuals

$N=$ total number of species

\subsubsection{Equitability (J):-}

The natural distribution of individuals among the species is called species evenness or equitability (Gupta and Shukla, 1991; Pielou, 1975).

$J=H^{\prime} / H(\max )$

$H(\max )=\log 2 S$

$S=$ Number of species in a quadrate

\subsubsection{Species richness:-}

The index of species richness (R) was calculated using the formula given by Menhinick (1964).

$R=S / \sqrt{N}$

$R=$ Richness index

$S=$ total number of species in the community

$N=$ total number of individuals summed over all species.

\subsubsection{Variety ratio:-}

It indicates the diversity of each species with reference to the total number of individuals in unit area. The high value indicates high diversity of species.

Variety ratio $=$ Total number of species $(S)$

Total number of individuals $(N)$

\subsection{Regenerative status:-}

The natural germination percentage, seedling establishment and casualty rate were calculated by counting methods. Randomly selected 10x10 meter quadrates were placed, and number converted into percentage.

\section{Results:-}

The Myristica swamps are the freshwater evergreen vegetated ecosystems predominated by the members of arborescent family Myristicaceae. The Myristica fatua var. maginifica, Gymnacrantheracanarica are the upper canopy dominant species, which constitute thick and continuous upper strata. These two species are structurally modified to survive in the swampy condition, especially with knee roots and silt roots (Plate 1.d \& e). The Myristicaceae members like Myristica malabarica, Knemaattenuta are commonly seen as dominant associate species; hence the name Myristica Swamps was derived. The non- Myristicaceae tree members like Lophopetalumwightianum, Lagerstroemia speciosa, Hydnocarpuspentandra, Holigarnaarnottiana, Syzygiumtravancoricum etc. are also well distributed in this forest type and sometime fall in the dominant category. The second and third strata are also well represented with younger members of these species with discontinuous canopy. The migrant and flexible species like VateriaindicaandHopeaparviflora, are also distributed with different magnifications, accordingly with successional status of the swamp. The ground vegetation is mostly represented with Lagenandraovata, Calamusrotang, Pinangadicksonii, Pandanuskaida. The lianas and climbers are mostly represented by Gnetumula, Entadarheedei, Jasminumcordifolium, and Piper spp. The floristic composition of ground vegetation and occurrence of the liana members are also dependent on degree of succession. Analysing the degree of similarity and dissimilarity between the isolated fragments of the swampy vegetation is typified into three categories according to the different degree of vegetational succession, namely Core vegetation, dominated with the species like Myristica fatua var. magnificaand Gymnacrantheracanarica, the transition vegetation has also the same dominant members with less degree of community status, while the edge vegetation is represented by dominant 
species Lagerstroemia speciosaand, Myristica fatua var. magnifica. The recorded relative occurrence and community status of Myristica fatua in terms of IVI are 86.45 in core area, 49.81 in transition zone and 22.34 in edge area. This also indicates a gradual decrease in occurrence and dominancy of the Myristica fatua var. magnifica. Gymnacrantheracanarica shows the value of 52.58, 27.02, and 19.89 respectively. Other associate species show different degrees of community status with respects to IVI value. (Table 1). As we look into the similarity of these three zones closely using the similarity index, the vegetative structure clearly represents an inverse relation. The core and the edge show very less similarity (29.5\%) compared to the core and transition zone (45.9\%). whereas the transition zone shows more affinity towards edge vegetation (72\%). This represents the invasion of other species from edge to the transition and this trend will later result in the extinction of the swamp and the replacement of the terrestrial forest vegetation.

Table 1:- The Community Status of Important Tree species of Myristica swamps in Three Succession Zone

\begin{tabular}{|l|l|c|c|c|}
\hline S1. No. & Binomial & Core Area & Transition Zone & Edge Area \\
\hline 1 & Aporusalindleyana & & 16.75 & 05.12 \\
\hline 2 & Chilocarpusdenudatus & 13.92 & 06.82 & 08.53 \\
\hline 3 & Derispinnatum & & 04.47 & 03.95 \\
\hline 4 & Gymnacrantheracanarica & 52.56 & 19.89 & 49.37 \\
\hline 5 & Holigarnaarnottiana & 16.10 & 06.38 & 24.15 \\
\hline 6 & Hopeaparviflora & - & 14.58 & 16.73 \\
\hline 7 & Hydnocarpuspentandra & 11.74 & 10.00 & 13.85 \\
\hline 8 & Lagerstroemia speciosa & 23.50 & 30.90 & 08.90 \\
\hline 9 & Lophopetalumwightianum & 33.75 & 09.48 & 19.85 \\
\hline 10 & Myristica fatuavar. magnifica & 86.43 & 22.34 & 59.81 \\
\hline 11 & Neolamarckiacadamba & 06.74 & - & 16.60 \\
\hline 12 & Syzygiumtravancoricum & - & 06.30 & 10.50 \\
\hline 13 & Vateriaindica & - & 08.00 & 20.49 \\
\hline 14 & Xanthophyllumarnottianum & - & 11.20 & 04.85 \\
\hline
\end{tabular}

The floristic composition and diversity of Myristica swamps also vary with vegetational succession, due to the isolation and fragmentation. The floristic composition of swamp includes 82 species belonging to 72 genera of 44 families. The distribution pattern of swampy vegetation shows, $32 \%$ of species random in occurrence, $65 \%$ in aggregate distribution and the remaining $03 \%$ with regular distribution pattern. This indicates the conservation value of the system; hence any alteration in ecosystem will lead to the massive extinction of species (Fig.1).

Fig.1:Vegetation Distribution pattern in Myristica Swamp

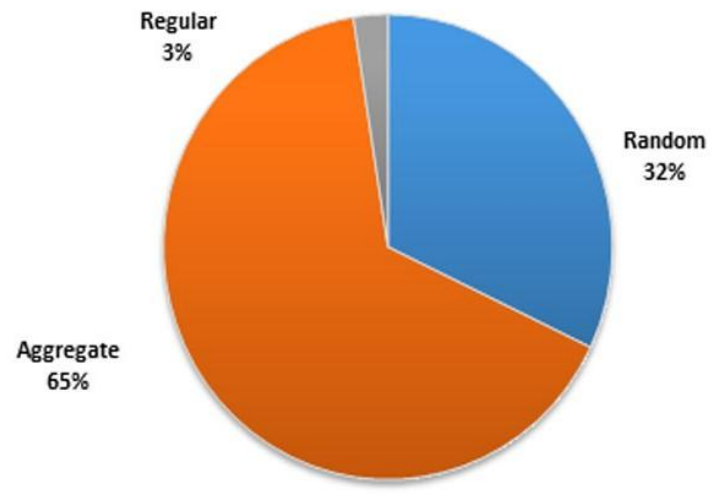

In the core area, the floristic diversity value, Simpson index is, 0.70 , while in the transition zone, the value is, 0.81 and in the edge area the highest values which are about equal to that of the evergreen forests of Western Ghats i.e. 0.94 have been recorded. The same increasing trend has been recorded in the Shannon-Weinner index. The respective values are $1.81,2.60$, and 3.48 . The Equitability value of core area is 0.66 , transition zone value is 0.77 
and edge area value is 0.85 .The species richness also shows a decrease from 1.0 in the core area, 2.1 in the transition and 4.0 in the edge zone. The variety ratio also shows the standard of increasing the value by the advancement of ecological succession; the respective values are $0.07,0.15$ and 0.29 . The density of tree species also shows changes with advancement of the ecosystem. In the core area of the swamp the tree density is 642 individuals per hectare, it decreases to 421 (68.5\% of core area) in transition zone and further to 314 (48.9\% of core area) in edge zone. The fragmentation and isolation of the specific ecological niche of the unique species of swamp ecosystems are declining or eroding gradually and lead to evolution and development of new vegetation and forest types (Fig.2).

Fig.2: Effect of fragmentation and isolation in florestic wealth and diversity of Myristica Swamps
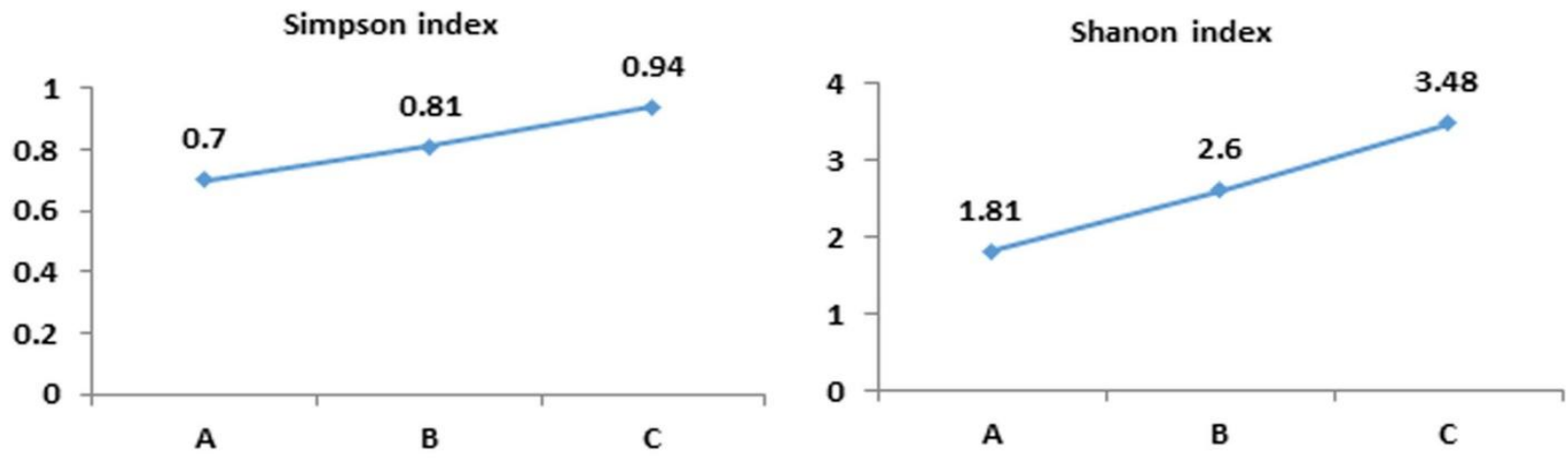

Equitability

Variety ratio
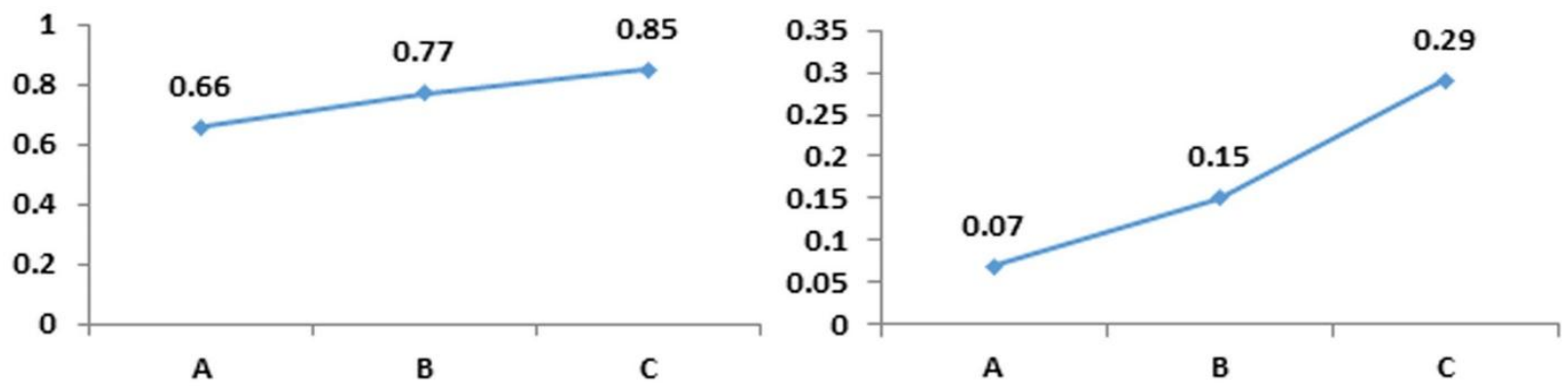

Species richness

Tree density
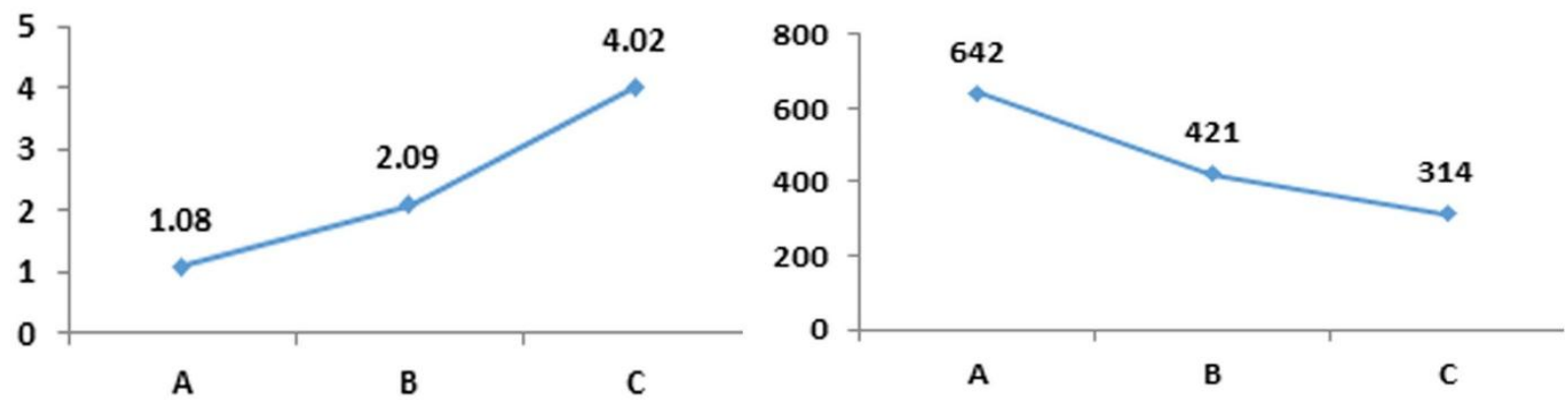

The study about the reproductive capacity and aggressive capacity of Myristica fatua shows that the species has high degree of reproductive capacity with gregarious flowering and good fruit setting. The average seeding is 56 seeds in one sq. meter area and $92 \%$ of these seeds are viable. The primary dispersal rate is 58-66 \%, mainly by Ocecerosgriseus (Hornbill), Phaethontidaepsittaciformes (Parrot) and Ratafaindica (Malabar Squirrel). The premature shedding due to the feeding of avian fauna like Phaethontidaepsittaciformes (Parrot),Ocecerosgriseus (Hornbill) and mammalian fauna like Ratafaindica (Malabar Squirrel), Rhesus macaqus(common Monkey) were 
also noticed. $48 \%$ of secondary dispersal was also noticed. The main dispersing agents are the common crustacean Barytelphusaguerini(tropical freshwater Crabs) and Rattusrattus(Rat). The germination percentage in natural condition is varies from $76.10 \%$ to $23.37 \%$ (core to edge) with an average value of 57.00 \% (Fig.3). The subsequent growth and establishment of seedlings up to two years were analysed and the same trend was observed as for Myristica fatua and it also varies in accordance with different degree of succession and fluctuation. In the core area, the casualty rate is $91.70 \%$, in the transition zone, $92.90 \%$ and $97.05 \%$ in edge area. (Fig.4)
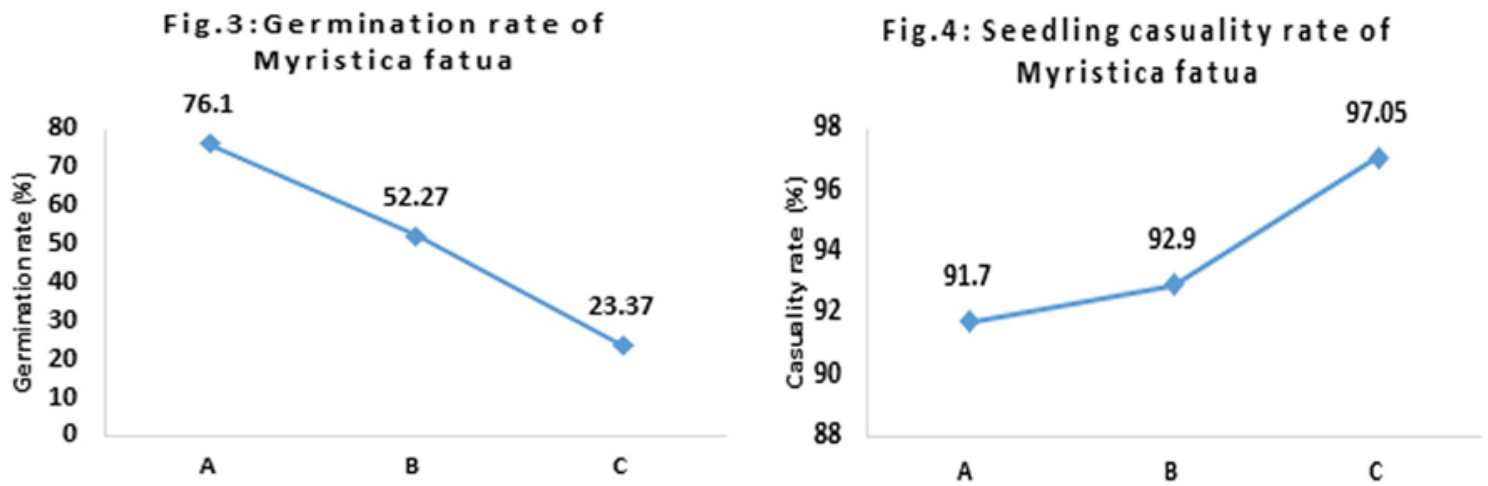

The Myristica swamps are the edaphic variant of tropical freshwater swamps and are evergreen in nature. These succumb to many threats due to the destructive and interactive face created by the natural and artificial factors. In turn it formulates various ecological and edaphological units. The population of unique species Myristica fatua var. magnifica in its different age class shows aggressive trends of declining population size through the advancement of transition of vegetation. In core area, the rate of population of Myristica fatua is $57 \%$. While in transition vegetation the rate of population of Myristica fatua is $41 \%$, in edge vegetation, surviving with other forest intruders, the Myristica fatuapopulation is drastically declines to $18 \%$ of the total population. The analysis shows that invading of other evergreen species to the swampy area will cause the switch over of the swampy vegetation to evergreen vegetation (Fig. 5\&6). The core area shows high degree of germination percentage and initial survival rate. The increased mortality rate indicates the specific ecological and edaphological requirements of the species for successful establishment. The fragmentation and isolation of this ecosystem has resulted in the decline in the number of individuals of structurally and functionally dominant specific species, Myristica fatua var. magnifica and hence it is considered as flagship species.

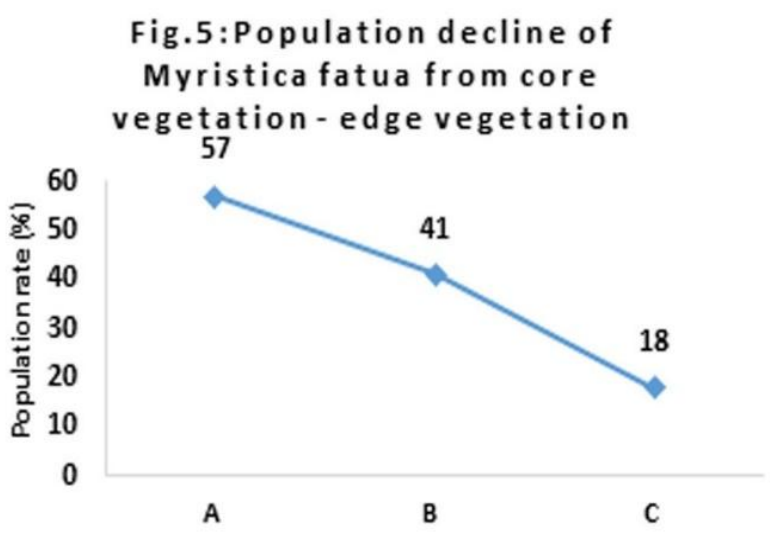

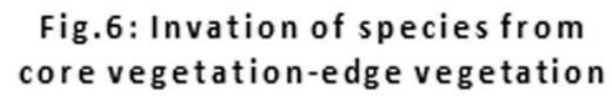

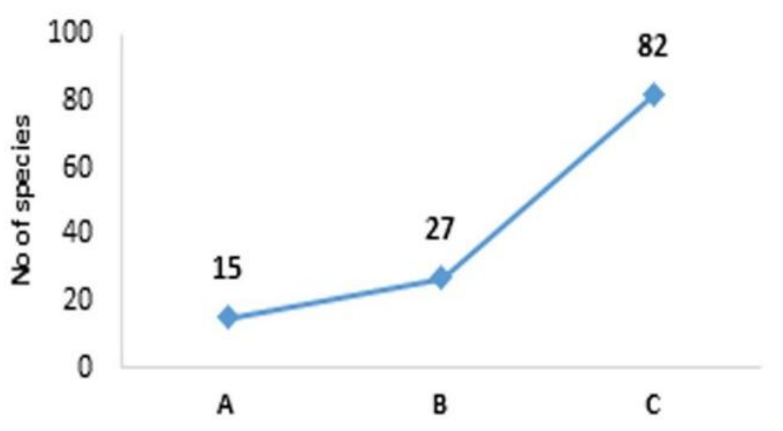




\section{Discussion:-}

Human alteration of the global environment has triggered six major extinction event in the history of the life and has caused wide spread changes in the abundance and distribution of the organisms (Han Olff and M.E Ritchie, 2002). Land use changes have the greatest impact on the biodiversity of the tropical forest area (Sala et al., 2000). Habitat fragmentation on a large scale occurs in the freshwater swamp ecosystem of the Western Ghats, which progressively gets subdivided into smaller and more isolated vegetation having interrupted matter and energy circulation. The changes in the ecological distribution has subsequently affected the floristic composition, vegetational structure and functional dynamism across other biotic and abiotic components stimulating a backdrop of natural patches created by changing landform and natural disturbance. This has led to different degrees of vegetational succession replacing the species that have survived in the swampy habitats. The fragmentation and isolation of ecosystem followed by the disruption and discontinuation of the flora and fauna will interrupt the functional dynamism of the ecosystem by checking energy and matter flow. These also result in the formation of different plant sub communities within the swamps itself .The different floristic elements occupy different space with different association having different boundaries, each with a varying degree of uniformity in structure and composition. By analysing the degree of similarity and dissimilarity between the floristic elements of fragments and isolated segments, a gradual gradation indicates the progressive trends of floristic fluctuation and succession. The vegetation is Phanero-thero type, dominated by trees and herbs, among which $80 \%$ of the arborescent species are paleoendemic and members of primitive families. Considering this primitive compositions, vegetation type, and antiquity, this swampy vegetation may be probably the remains of the most ancient forest of the Western Ghats. These unique and vital forest types are on the verge of extinction due to natural and manmade reasons.Nevertheless the fragmented freshwater swamps preserve remnants of vegetation thereby maintaining the conservation status of rare ecosystems to some extend.

The changing community structure of Myristica swamps are the primary driving force of vegetational changes, while direct effect of human activities like artificial constructions, habitat destruction, alternation of the land use pattern, exploitation for livelihood and introduction of alien species are secondary forces of change. Hobbs and Yates in 2003 and Laurence et al. in 2002 observed the same in other forest ecosystems. The fragmentation is also creating modified plant dynamism owing to the changes in the atypical organization in the size, shape and isolation of the forest patches. The edge effect and following invasion of other species have altered the internal microclimate and also the nutrient status of the soil system. These changes, the disproportionate establishment of plant species immediately affect the establishment of flagship species, Myristica fatua var. magnifica, the dominant species of the core area is being locally extinct in the edge area. Even in the transition zone, the number of the individual are not enough to specify the characteristic features of the swamp. The gradation of the floristic diversity indices and tree density indicates that this process is causing difference not only in the diversity but also in the bio wealth of core, transition and edge area. The change in the important value index indicates the changes in the community status of the common species of the swamp. The fragmentation of the swamp has a tendency to lose original species like Myristica fatua var. magnifica, Gymnacrantheracanarica, and gain new species like Lophopetalumwightianum, Vateriaindica, Hopeaparviflora, the species that are capable of establishing fragmented swamp having new ecology and edaphology, initially by altering the water regime due to the acceleration in the silting and breakage of water flow. This alternate pattern of water flow leads to changes in normal drainage pattern and creates a modified substrate and ultimately leads to reduction of new environment for the plant colonization. The modified water regime results in the removal of specific underground swampy amphibian vegetation and can act as a focus for invasion of new species of terrestrial vegetation. The requisite micro niche of some vital faunal association also disturbed. The secondary seed dispersal of Myristica fatua var. magnificawere affected,hence successful establishment of the flagship species is affected in recruitment stage. The changes will also lead to changes in the humus deposition and decomposition rate. The flood washed off most of the debris and decrease saprophytic faunal diversity. This has altered the fauna abdication as well as the seed bed characterization resulting in mineral inequilibrium of soil system. The changes in the floristic composition and vegetational structure, upon the fragmentation of the Myristica swamp, and the production of remnant vegetation patches are likely to result in more flexible species getting established. Lovejoy et al., 1986 had reported that fragmentation in the tropical forest resulting in the rapid growth of vine and secondary vegetation in a 10-25.m, strip around the remnant edge. The freshwater swamps of Kerala once continuously distributed in low elevated lateritic hill rocks of the Western Ghats, were fragmented due to urbanization and other anthropogenic or natural reasons and are now distributed as relic vegetation, both in natural forest areas of southern Western Ghats and in the midst of the populated areas as sacred groves. The plant species Myristica fatua var. magnifica can only survive and tend to occur only in this specific ecosystem, hence they termed as 'flagship species'. In addition to this an interactive faunal association of Barytelphusaguerini affects the secondary seed dispersal of Myristica fatua var. magnifica. The fragmentation in 
swamp ecosystem is altered and a modified energy flow is created by generating a dispersal barrier for different life forms especially for flagship species or the keystone species.

\section{Conclusion:-}

Myristica Swamps are unique fresh water phyto-geographic ecosystems of Western Ghats, once distributed in low laying areas of Kerala State in a continuous manner. The floristic composition, ecology and edaphology are specific with high occurrence and distribution of Myristicaceae members, especially of flag ship species, Myristica fatua var. magnifica. The members are structurally modified due to inundated during greater part of the year. Presently, due to natural and manmade changes these are under threat and in path of extinction. The existing treasure home of biowealh, fresh water swamps, requires more attention to conserve, especially to check the local extinction of a few vital species and its associate. The typical swamps are characterised by low floristic diversity and high stem density. The vegetation is amphibian features, adapted to survive in marshy conditions. The germination and recruitment of new members of the important species are related to general ecology and physical edaphology including some faunal associations. These forest relics are facing various levels of disturbance, among which fragmentation is in prime position, which would be causative factor regarding the loss of swamp ecosystems. The fragmentation and isolation alter floristic structure, composition, micro climate, and water regime. These initial floristic, ecological and edaphological changes ends with formation of new ecosystem with common floristic composition, terrestrial ever green forest.

\section{Acknowledgement:-}

The authors are grateful to Department of Biotechnology Government of India for funding. Thanks are also due to the director Jawaharlal Nehru Tropical Botanic Garden and Research Institute, Palode, Thiruvananthapuram for research facilities and to Kerala forest department for their field support

\section{Reference:-}

1. Barbour, M.G., Burk, J.H. and Pitts, W.D., (1980). Terrestrial Plant Ecology, 2nd edition. Benjamin/Cummings, Menlo Park, California, USA.

2. Bourdillion, T.F., (1908). The forest trees of Travancore Govt. Press, Trivandrum xxxii+456pp.

3. Champion, H.G., Seth, S.K., (1968). A revised survey of the forest type of India Government of india.xxiii+404pp.

4. Chandran, M.D.S., Mesta, D.K., (2001). On the conservation of the Myristica swamps of the Western Ghats. In: Forest Genetic Resources: Status, Threats, and Conservation Strategies. Eds. Uma Shanker, R., Ganeshaiah, K.N., and Bawa, K.S. Oxford and IBH,New Delhi: 1-19

5. Chandran M.D.S., Rao, G.R., Gururaja. K.V., Ramachandra, T.V., (2010). Ecology of the Swampy Relic Forests of Kathalekan from Central Western Ghats, India. Bioremediation, Biodiversity and Bioavailability 4 (Special Issue I), Global Science Books, 54-68.

6. Gadgil, M., Chandran. M.D.S., (1989). Environmental impact of forest based industries on the evergreen forests of Uttara Kannada district, a case study (Final Report). Department of Ecology and Environment, Government of Karnataka, Bangalore.

7. Chandran, M.D.S., Gadgil, M., (1998). Sacred groves and sacred trees of Uttara Kannada. In: B. Saraswati (ed) Lifestyle and Ecology, Indira Gandhi National Centre for Arts, New Delhi.

8. Gupta, O.P., Shukla. R.P., (1991). The composition and dynamics of associated plant communities of sal plantations. Tropical Ecology 32: 296-309.

9. Han Olff., Ritche, M.E., Herber, H.T., (2002).Global environmental controls of diversity in large herbivores. Nature 415: 901-904.

10. Hobbs, R.J., Yates, C.J., (2003). Impacts of ecosystem fragmentation on plant populations: generalising the idiosyncratic. Aust J Bot 51: 471-488.

11. Krishnamoorthy, K., (1960). Myristica swamps in the evergreen forests of Travancore. Indian Forester 86(5): 314-315.

12. Laurance, W.F., William, G.B., Delamonica, P., Olivera, A., Gascon, C., Lovejoy, T.E., Pohl, L., (2002). Effect of a severe drought on Amazonian forest fragments and edges. Journal Tropical Ecology.17:771-785.

13. Lovejoy, T. E., (and 10 others). (1986) Edge and other effects of isolation on Amazon forest fragments. In Conservation biology: the science of scarcity and diversity (ed. M. E. Soule'), pp. 257-285.

14. Menhinick, E.F., (1964). "A comparison of some species diversity indices applied to samples of field insects," Ecology, 45: 858-862 
15. Nayar, M.P., Sastry, A., (1988). Red Data Books of Indian Plants. Vol II, Botanical Survey of India, Calcutta. p. 109-118,

16. Nayar, M.P., Sastry, A., (1990). Red Data Books of Indian Plants. Vol III, Botanical Survey of India, Calcutta.

17. Nayar, M.P., Sastry, A., (1987). Red Data Books of Indian Plants. Vol I, Botanical Survey of India, Calcutta. p. 147-159.

18. Pascal, J. P., (1984). Les forêtsdenseshumidessempervirentes des Ghâtsoccidentaux. Ecologie, structure, floristique ET succession. Inst. fr.Pondichéry, trav. sec. sci. tech. 20. (English version: 1988. Wet evergreen forests of the Western Ghats of India.)

19. Pielou, E.C., (1975). Ecological diversity. John Willey and sons. New York

20. Ramesh, B.R., Pascal, J.P., (1997). Atlas of the Endemics of the Western Ghats (India). Distribution of tree species in the evergreen and semi evergreen forests. K.J French Institute, Pondicherry. 403 pp.

21. Sala, O.E., Chapin, I.F.S., Armesto, J.J., Berlow, E., Bloomfield, J., Dirzo, R., Huber Sanwald, E., Huenneke, L.F., Jackson, R.B., Kinzig, A., Leemans, R., Lodge, D.H., Mooney, H.A., Oesterheld, M., Leroy Poff, N., Sykes, M.T., Walker, B.H., Walker, M., Wall, D.H., (2000). Global biodiversity scenarios for the year 2100. Science 287 (5459), 1770-1774. S

22. Saldanha, C.J., (1984). Flora of Karnataka.Oxford and IBH publishing co, New Delhi. Vol. I.

23. Santhakumaran, L.N., Singh, A., Thomas, V.T., (1995). Description of a sacred grove in Goa (India), with notes on the unusual aerial roots produced by its vegetation. Wood. OctDec: 24-28

24. Santhakumaran, L.N., (1996). Marine wood-borers from mangroves along Indian coasts. Journal of the Indian Academy of Wood Science 26 \& 27: 1-14.

25. Sasidharan, N., Sivarajan, V.V., (1996). Flowering Plants of Thrissur Forests. Scientific Publishers, Jodhpur.

26. Sorenson, H., (1948). Studies on ecology of Danish water and bod masses.Dansk. Bot. Ark. 12:101

27. Shannon, C.E., Weiner. W., (1963). The Mathematical Theory of Communication. University of IllinoisPress, Urbana, U.S.A.

28. Simposon, E.H., (1949). Measurement of diversity. Nature 163: 688

29. Whiteford, P.B., (1948). Distribution of wood land plants in relation to succession and clonal growth. Ecology 30:199-208.

30. Vasudeva, R., Raghu, R.,.Dasappa, H.B., Umasankar, R., and Ganesh, N., (2001). Population structure, reproductive biology and conservation of Semicarpuskathalekunensis: a critically endangered freshwater swamp tree species of the Western Ghats In: Umasankar, R., Ganeshaih, K.N., and Bawa, K.S., (cds), Forest Genetic resources: Status, Threat and Conservation strategies, Oxford and IBH publications, New Delhi. 211-233 pp. 